\title{
Reduced Immunoglobulin M Is Associated with Sinus Mucosal Thickening, Osteitis and Sinus Surgery in Patients with Common Variable Immunodeficiency
}

\author{
John B. Hagan ${ }^{a}$ Miguel A. Park ${ }^{a}$ Hirohito Kita ${ }^{b}$ Norbert G. Campeau ${ }^{c}$ \\ ${ }^{\mathrm{a}}$ Department of Medicine, Division of Allergic Diseases, and Departments of ${ }^{\mathrm{b}} / \mathrm{mm}$ unology and \\ ${ }^{\mathrm{C}}$ Radiology, Mayo Clinic and Foundation, Rochester, Minn., USA
}

\section{Key Words}

Common variable immunodeficiency $\cdot$ Chronic sinusitis • Immunoglobulin M

\begin{abstract}
Background: Although common variable immunodeficiency (CVID) is associated with sinopulmonary disease, there are no previous systematic evaluations comparing computed tomographic (CT) sinus imaging with immunoglobulin measurements in patients with this condition. Methods: We performed a retrospective review by a blinded observer using the Lund-Mackay numerical scoring scale as well as a visual scale for remodeling changes in the paranasal sinus bone on CT scans in CVID patients. Results: The sinus CT scans of 19 subjects ( 9 males, 10 females; median age at diagnosis 34 years) are described. There was an inverse relationship between serum IgM and sinus mucosal thickening as described by the Lund-Mackay scale ( $R=-0.6398 ; p=0.0032)$. Osteitis of the paranasal sinus bone was almost exclusively found in patients with a reduced serum IgM level of less than $25 \mathrm{mg} /$ $\mathrm{dl}(p=0.0074)$. Conclusion: This is the first study to show that sinus mucosal thickening on CT in patients with CVID is inversely related to serum IgM levels.
\end{abstract}

Copyright $\odot 2009$ S. Karger AG, Base
(C) 2009 S. Karger AG, Basel

$1018-2438 / 10 / 1521-0081 \$ 26.00 / 0$

Fax +41613061234

E-Mail karger@karger.ch

www.karger.com
Accessible online at:

www.karger.com/iaa

\section{Introduction}

Common variable immunodeficiency (CVID), previously recognized in adults as idiopathic late-onset immunoglobulin deficiency, has been an important cause of recurrent and chronic sinusitis for many years $[1,2]$. CVID is equally represented in both sexes, although some authors have recently reported that female patients with this disorder may have a predominance of switched memory cells when compared to males [3]. CVID has a prevalence ranging from 1 per 50,000 to 1 per 200,000 and is diagnosed by the presence of hypogammaglobulinemia of 2 or more immunoglobulin isotypes (low IgG, IgA and/or $\operatorname{IgM}$ ), recurrent sinopulmonary infections and impaired functional antibody responses to vaccine antigens. Other clinical findings, such as autoimmunity, granulomatous disease and neoplasia, may be present [4]. Of the 248 CVID patients reported by CunninghamRundles and Bodian [5], 98\% had experienced recurrent bronchitis, sinusitis or otitis. Other important studies have confirmed the association between CVID and recurrent sinopulmonary infections [6-8]. Spirometric and chest radiologic findings of patients with CVID have previously been described [9]. Endoscopic findings of sinus disease have been reported [10]. Bondioni et al. [11] are 
the only authors to date to describe the radiologic findings of CVID using computed tomography (CT) of the paranasal sinuses. However, the immunoglobulin values of the subjects were not provided in the report [11]. Chee et al. [12] reported results of immune tests in patients with refractory sinusitis in a tertiary care setting where 9.9\% of subjects were found to have CVID. Sinus mucosal thickening was evaluated in subjects from the whole group but was not specifically characterized for patients with CVID [12]. Thus, sinus-specific radiologic findings including sinus mucosal thickening have not previously been compared to immunoglobulin values in patients with CVID.

Carsetti and co-workers [13] observed that 3 specific groups of patients with a predisposition to severe pneumococcal infections (infants, asplenic patients and a subset of CVID patients) had significant reductions or an absence of IgM memory B cells. In a separate report, this group further demonstrated that IgM memory B cells and antipneumococcal polysaccharide $\operatorname{IgM}$ antibodies were important in the protective response of CVID patients to bacterial pneumonia [14]. Though the IgM levels were different in CVID patients who had recurrent infections compared to those who did not, the results did not reach statistical significance, probably due to the small sample size [14]. Detkova et al. [15] also found frequent occurrence of chronic lung disease defined by bronchiectasis and bronchial obstruction in patients with absent or low memory B cells, although that study did not differentiate IgM memory B cells. There appeared to be no association between the numbers of memory B cell subsets and prior pneumonia or severe infections in another group of CVID patients evaluated by Cunningham-Rundles and co-workers [3].

Because of the paucity of data concerning radiologic descriptions of the sinuses in CVID, we describe here the findings of CT of the sinuses in CVID patients and the relationship between sinus mucosal thickening and serum IgM.

\section{Patients and Methods}

From the Mayo Clinic primary immunodeficiency database, we identified 19 patients with CVID who underwent CT of the sinuses at our institution from June 2003 to November 2007. The data were retrieved in accordance with Institutional Review Board approval and the guidelines of the Health Insurance Portability and Accountability Act. All patients carried an immunologist's diagnosis of CVID, which included decreases in serum IgG and IgA 2 standard deviations below the mean values of normal
Table 1. Patient characteristics $(\mathrm{n}=19)$

$\begin{array}{lc}\text { Age at symptom onset, years } & 22(10-36) \\ \text { Age at diagnosis of CVID, years } & 34(17-51) \\ \text { Age at sinus CT, years } & 52(39-56) \\ \text { Males } & 9(47) \\ \text { Females } & 10(53) \\ \text { Smoking status, n } & \\ \text { Never } & 17(85) \\ \text { Former } & 1(5) \\ \text { Current } & 2(10) \\ \text { IgG at diagnosis }{ }^{\mathrm{a}}, \mathrm{mg} / \mathrm{dl} & 167(45-391) \\ \text { Serum immunoglobulin values at time of study } \\ \text { IgG, mg/dl } & 754(122-1,010) \\ \text { IgA, mg/dl } & 1(1-2) \\ \text { IgM, mg/dl } & 11(5-46) \\ \text { IgE, kU/l } & 2(2-2) \\ \text { Pulmonary function }{ }^{b} & \\ \text { FVC, \% predicted } & 97(87-101) \\ \text { FEV }, \% \text { predicted } & 94(75-103) \\ \text { FEV/FVC } & 80(71-89) \\ \text { FEF 25-75, \% predicted } & 88(56-104) \\ \text { DLCO }, \% \text { predicted } & 93(75-99) \\ \text { Lund-Mackay score } & 6(4-11)\end{array}$

Values are medians and IQRs in parentheses or numbers of patients with percentages in parentheses, as appropriate. Normal values of serum $\operatorname{IgG}, \operatorname{IgA}$ and $\operatorname{IgM}$ at our institution for age $\geq 18$ years based on 2 SD from the mean: IgG, $600-1,500 \mathrm{mg} / \mathrm{dl}$; IgA, 50-400 mg/dl; IgM, 50-300 mg/dl. Reference values of serum IgE: mean 13.2, +1 SD 41, +2 SD $127 \mathrm{kU} / 1$. FVC = Forced vital capacity; $\mathrm{FEV}_{1}=$ forced expiratory volume in $1 \mathrm{~s} ; \mathrm{FEF}=$ forced expiratory flow; $\mathrm{DLCO}=$ diffusing capacity of the lung for carbon monoxide.

${ }^{\mathrm{a}} \mathrm{n}=14$ with documented level at diagnosis. Remaining 5 values were the lowest documented values. Otherwise, all values were at the time of study and all study subjects were receiving intravenous replacement. ${ }^{\mathrm{b}} \mathrm{n}=18$ with available spirometric values. ${ }^{\mathrm{c}} \mathrm{n}=17$ with available DLCO.

subjects. All patients were clinically symptomatic after the age of 2 years and had had other defined causes of hypogammaglobulinemia excluded, consistent with European Society for Immunodeficiencies guidelines [16]. Pre- and postvaccination responses to protein and polysaccharide antigens were not available for all subjects. Patient medical records were reviewed to obtain clinical, laboratory and radiologic data, and key patient characteristics are included in table 1 .

Pulmonary function tests were performed according to the current American Thoracic Society guidelines [17]. The diffusing capacity of the lung for carbon monoxide was measured using the single-breath technique.

Coronal sinus CT was performed according to an institutional protocol (no intravenous contrast, helical acquisition from the hard palate to the top of the frontal sinus, caudocranial direction, coronal reconstructed images of 1-mm thickness, 150-mm field of view), with all scans reviewed by a board-certified neuroradi- 

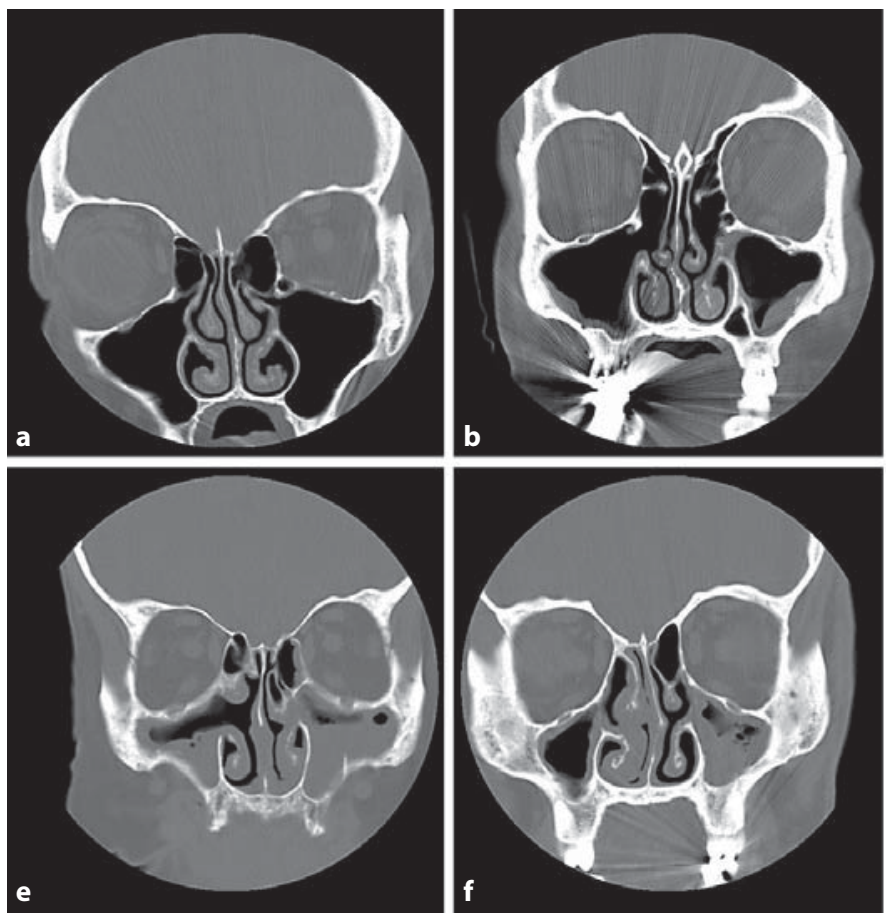

Fig. 1. Noncontrast coronal sinus CT scans. a This is a normal study. The paranasal sinuses are clear. A small Haller air cell (normal variant) is present along the roof of the left maxillary sinus, without evidence of significant narrowing of the left maxillary infundibulum. b Postoperative changes of bilateral maxillary antrostomies with partial ethmoidectomies. Mild mucosal thickening involving the maxillary sinuses is present bilaterally and is greater on the left. There is mild hypoplasia and paradoxical rotation of both middle turbinates. The nasal septum is deviated to the right. c Bilateral, medial antrostomies are present. There is moderate membrane thickening which opacifies the inferior half of both maxillary sinuses. Membrane thickening and frothy-appearing material are present within an anterior left ethmoid air cell. There is mild chronic osteitis involving the lateral wall of both maxillary sinuses. d Membrane thickening results in complete opacification of the right maxillary sinus. There is a small amount of membrane thickening within the inferior left maxillary sinus. Postoperative changes of bilateral medial antrectomies, bilateral middle turbinectomies and partial inferior ethmoidectomies. e Moderate mucosal thickening with air fluid lev-
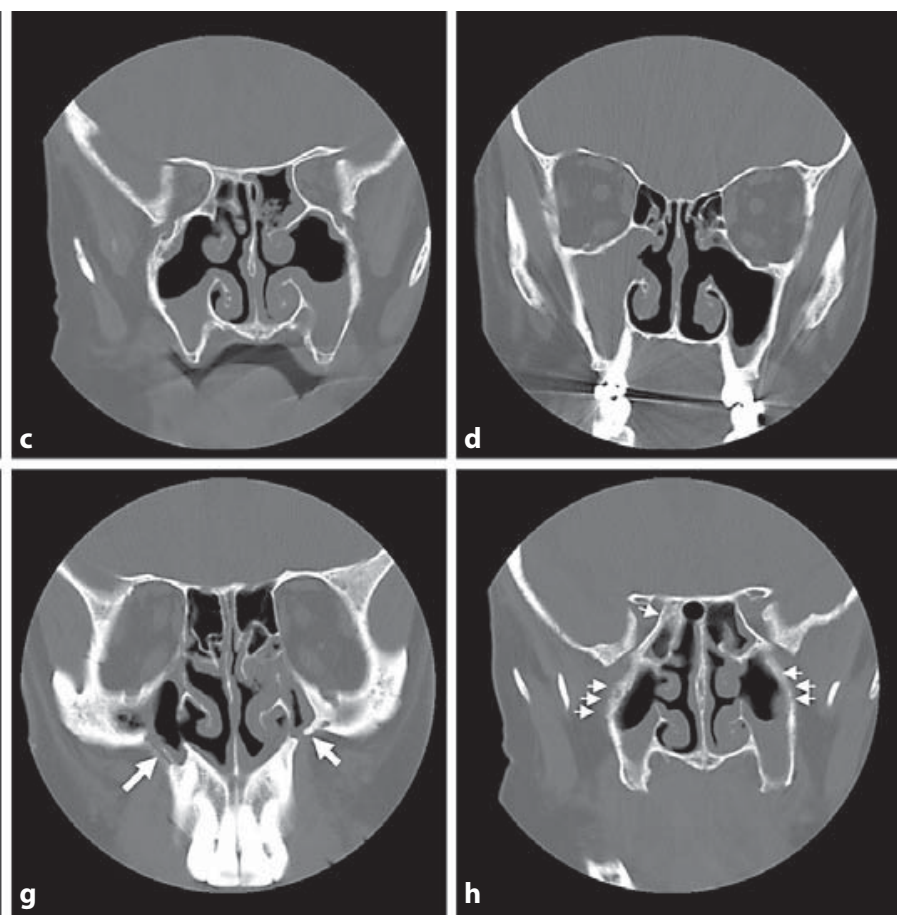

els within the maxillary sinuses, slightly more marked on the left, consistent with acute sinusitis. Postoperative changes include bilateral maxillary antrostomies and adjacent partial ethmoidectomies. Mild scattered mucosal thickening is noted within residual ethmoid air cells. Chronic osteitis involves the roof and lateral wall of both maxillary sinuses. $\mathbf{f}$ Postoperative changes include a bilateral uncinectomy. Moderate mucosal thickening with frothyappearing fluid is present in the left maxillary sinus. There is minimal mucosal thickening in the right maxillary sinus. The nasal septum is deviated toward the left. g Postoperative changes include a bilateral Caldwell-Luc procedure (arrows) and bilateral nasal antral windows, patent on the right but occluded by membrane thickening on the left. There is mild to moderate membrane thickening within the left nasal cavity and inferior ethmoid air cells. There is hypoplasia of the maxillary sinuses, greater on the left, and mild asymmetric enlargement of the left orbit compared to the right. Findings are consistent with sequelae of chronic maxillary atelectasis. $\mathbf{h}$ Scattered areas of thickening and sclerosis involve the walls of the maxillary and right sphenoid sinuses (small arrows), consistent with chronic osteitis. ologist (N.G.C.) who was blinded to the clinical and laboratory data of the study subjects. Each scan was assigned a CT score based on the Lund-Mackay staging scale, which provides the sum of the values for visualized mucosal thickening $(0=$ no abnormality; 1 = partial abnormality; 2 = total opacification) in each of the paranasal sinuses and the presence or absence of obstruction of the ostiomeatal units ( $0=$ not obstructed; $2=$ obstructed $)$. Any visible mucosal thickening was considered a partial abnormality if the specific paranasal sinus was not totally opacified. This radiologic grading scale ranges from 0 to 24 [18]. In addition, scans were assessed for radiologic evidence of osteitis of the paranasal sinus bone. Osteitis of the paranasal sinus walls manifests radiologically as demineralization and loss of trabeculae in the early stages, progressing to areas of focal sclerosis and, later, diffuse sclerosis and bone thickening. This corresponds to the histologically observed changes in the bone matrix, including rarefaction of bone with loss of trabeculae in early osteitis and later various degrees of sclerosis, neo-osteogenesis and bone remodeling [19]. Osteitis was graded using the following visual scale for each sinus affected: 0 = no evidence of osteitis; 1 = mild osteitis [osteopenia, 


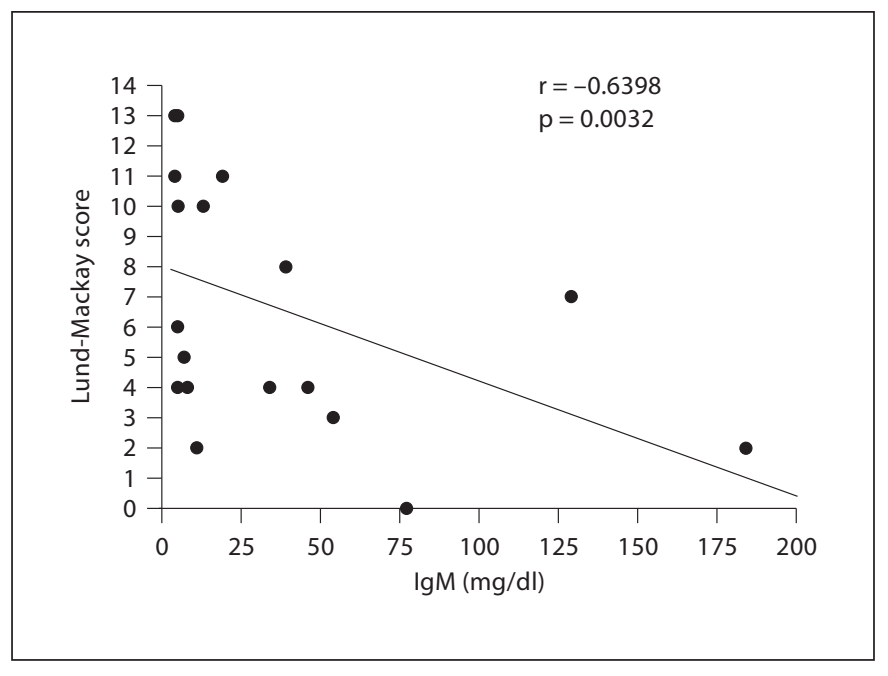

Fig. 2. Association between IgM levels and sinus mucosal thickening.

mild bone thickening ( $<3 \mathrm{~mm}$, mild sclerosis)]; 2 = marked osteitis (osseous thickening greater than $3 \mathrm{~mm}$, advanced sclerotic changes). For subjects who had radiologic evidence of osteitis in more than 1 sinus cavity, the number for each affected sinus was added to yield a total score for osteitis for a maximal score of 8 in this study, as no individual was found to have osteitis in more than 4 distinct paranasal sinuses.

\section{Statistical Analysis}

Unless otherwise specified, data are summarized as the raw numerical values with percentages or median values and interquartile ranges (IQRs). Differences between grades of osteitis were assessed using the Wilcoxon rank sum test when comparing 2 groups. Correlations between IgM values and sinus CT scores were calculated using the Spearman rank correlation test due to skewed distributions. A p value of less than 0.05 and an $r$ value of greater than 0.04 were considered significant. Statistical analyses were performed using JMP software release 7.0.1 (Statistical Discovery $^{\mathrm{TM}}$, SAS Institute, Cary, N.C., USA).

\section{Results}

Specific radiologic findings of patients with CVID are shown in figure 1 . Spirometric values are listed in table 1; median values were within the normal limits. Mucosal thickening was present to some extent on 18 of 19 sinus scans (95\%), with a median Lund-Mackay score of 6 (IQR 4-11). There was a significant inverse correlation between the serum IgM level and Lund-Mackay score (fig. 2).

In order to compare the relationship between IgM and osteitis observed on sinus CT radiography, subjects were

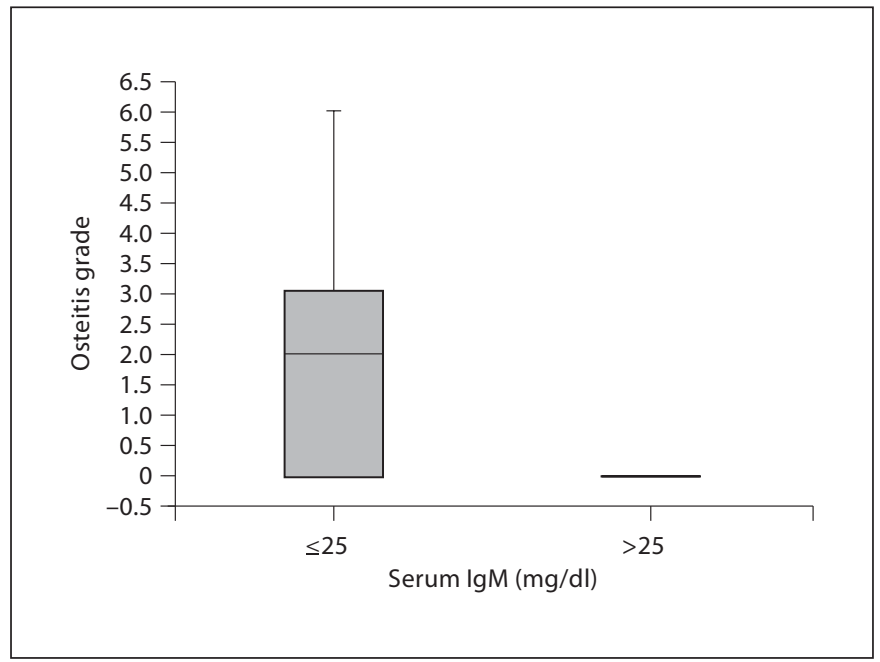

Fig. 3. Association between IgM levels and osteitis on sinus CT.

arbitrarily divided into 2 groups of relatively equal size, i.e. those with IgM values $>25 \mathrm{mg} / \mathrm{dl}$ and those with IgM values $\leq 25 \mathrm{mg} / \mathrm{dl}$. Median ages and IQRs of the $>25$ and $\leq 25 \mathrm{mg} / \mathrm{dl}$ groups were 43 (32-53) and 55 (42-59) years, respectively, suggesting a relationship with age, though this possible relationship was not statistically significant ( $\mathrm{p}=0.087$ ). No patient from the $>25 \mathrm{mg} / \mathrm{dl}$ group had previously undergone sinus surgery. In contrast, 6 of the 11 subjects with IgM values $\leq 25 \mathrm{mg} / \mathrm{dl}$ had radiologic evidence of previous sinus surgery. Reduced IgM was associated with radiologic evidence of osteitis (fig. 3). Although this finding was more common in subjects who had undergone sinus surgery, radiologic evidence of osteitis was present in 2 individuals who had not previously undergone sinus surgery. Using nonparametric analyses, there were no statistically significant differences between $\operatorname{IgG}$ values at the time of the study and either sinus mucosal thickening or osteitis $(\mathrm{p}>0.05)$. As a control group of patients, 17 subjects of comparative ages and gender who fulfilled the study criteria for CVID and who had not undergone a sinus CT with a report available at the Mayo Clinic, Rochester, were identified. IgG and IgM values were also measured in these 17 subjects. Using nonparametric analyses, there were no statistically significant differences between IgG or IgM when comparing values of the 17 control CVID subjects and the 19 subjects included in this study $(\mathrm{p}>0.05)$. 


\section{Discussion}

This is the first report comparing sinus mucosal thickening on sinus CT to serum immunoglobulin levels in patients with CVID. Ninety-five percent of the subjects studied had evidence of sinus mucosal thickening. Serum IgM levels were inversely related to sinus mucosal thickening. Patients with reduced serum IgM were more likely to have radiologic evidence of previous sinus surgery and demonstrated osteitis of the paranasal sinus bone. There were no relationships between mucosal thickening or osteitis and gender. The high frequency of sinus mucosal thickening is consistent with the study of Bondioni et al. [11], where 25 of 27 patients (93\%) were found to have sinus mucosal thickening. Although these numbers likely represent referral bias of patients selected on the basis of upper respiratory symptoms, they do support the utility of sinus tomography in the documentation of sinus disease, which may be very helpful supporting evidence in the clinical diagnosis of patients with CVID.

Rhinosinusitis has been estimated to affect approximately 31 million patients in the USA each year [20]. Radiologic evidence of sinus mucosal thickening remains an objective hallmark of this disorder [21]. Although the cause of chronic rhinosinusitis remains an area of active study, the etiology may be multifactorial and may include modulators of infection and inflammatory processes within and beyond the sinus cavities. Using a model of humoral immunodeficiency such as CVID, we present evidence suggesting the possibility of an intimate relationship between sinus mucosal thickening and serum IgM levels.

The findings from this study could have important clinical implications in the evaluation and treatment of patients with humoral immunodeficiency. Though sinus mucosal changes were seen in nearly all subjects, the majority of subjects had no evidence of reduced lung function. This suggests that sinus CT changes may represent a more sensitive marker of humoral immunodeficiency when compared to airflow obstruction or bronchiectasis. In fact, airflow obstruction and bronchiectasis may represent relatively advanced stages in the progression of sinopulmonary disease in CVID patients. This study also provides evidence that sinus CT changes persist despite treatment with standard regimens of intravenous immunoglobulin. This finding is consistent with those of Quinti et al. [7], who documented an increase in the prevalence of chronic sinusitis and lung disease in patients with CVID despite long-term treatment with immunoglobulin therapy. Current preparations approved in the USA contain significant amounts of $\operatorname{IgG}$ but not $\operatorname{IgM}$. Since immunoglobulin preparations containing IgM have the ability to activate complement, an IgM-enriched preparation may provide a more rapid or robust response to encapsulated pathogens [22]. Streptococcus pneumoniae, an encapsulated organism, is commonly isolated in patients with rhinosinusitis and is a prominent cause of community-acquired pneumonia [20, 23].

The limitations of the present study include the retrospective nature of the analyses, with the potential for referral bias in a tertiary care setting. In addition, there was a relatively low number of subjects in this study. Only subjects who had already undergone sinus radiography were included in this study. Thus, the relationship between reduced IgM and sinus CT findings may be limited to subjects with CVID suffering from symptoms suggestive of sinusitis. The fact that pre- and postvaccination titers were not available for all patients may be viewed as a limitation. However, only patients who had a characteristic clinical history of CVID in the absence of X-linked (Bruton's) agammaglobulinemia and secondary causes of hypogammaglobulinemia, including gastrointestinal or urinary protein loss, were included. In addition, experts in the field have reported positive vaccination responses to occur in subjects with a diagnosis of CVID [24]. At the time of patient evaluation in the present study, B cell assessment to determine the percentage of switched memory B cells was not clinically available at our institution for all subjects. The criteria for osteitis were not based on a validated scale but rather on the empiric observation of a single observer.

Despite these limitations, this is the first study to show that serum IgM levels are inversely related to sinus mucosal thickening on CT in patients with CVID. Osteitis of the paranasal sinus bone appeared to be limited to subjects with IgM values less than $25 \mathrm{mg} / \mathrm{dl}$ in this group of CVID patients. Radiologic evaluation in a larger cohort of CVID patients is required to validate these findings and provide further insight into the immunological mechanisms of sinus disease in patients with CVID and, potentially, other humoral immunodeficiencies.

\section{Acknowledgments}

Funding was provided by the Departments of Medicine, Radiology and Immunology, Mayo Clinic and Foundation, Rochester, Minn., USA. The authors thank Roshini S. Abraham, PhD (Cellular and Molecular Immunology Laboratory, Mayo Clinic, Rochester), for her valuable assistance in reviewing the manuscript. 


\section{References}

$\checkmark 1$ Hermans PE, Diaz-Buxo JA, Stobo JD: Idiopathic late-onset immunoglobulin deficiency. Clinical observations in 50 patients. Am J Med 1976;61:221-237.

$\checkmark 2$ Janeway CA, Apt L, Gitlin D: Agammaglobulinemia. Trans Assoc Am Physicians 1953; 66:200-202.

-3 Sanchez-Ramon S, Radigan L, Yu JE, Bard S, Cunningham-Rundles C: Memory B cells in common variable immunodeficiency: clinical associations and sex differences. Clin Immunol 2008;128:314-321.

$\checkmark 4$ Park MA, Li JT, Hagan JB, Maddox DE, Abraham RS: Common variable immunodeficiency: a new look at an old disease. Lancet 2008;372:489-502.

$\checkmark 5$ Cunningham-Rundles C, Bodian C: Common variable immunodeficiency: clinical and immunological features of 248 patients. Clin Immunol 1999;92:34-48.

-6 Chapel H, Lucas M, Lee M, Bjorkander J, Webster D, Grimbacher B, Fieschi C, Thon V, Abedi MR, Hammarstrom L: Common variable immunodeficiency disorders: division into distinct clinical phenotypes. Blood 2008;112:277-286.

-7 Quinti I, Soresina A, Spadaro G, Martino S, Donnanno S, Agostini C, Claudio P, Franco D, Maria Pesce A, Borghese F, Guerra A, Rondelli R, Plebani A; Italian Primary Immunodeficiency Network: Long-term follow-up and outcome of a large cohort of patients with common variable immunodeficiency. J Clin Immunol 2007;27:308316.

$\checkmark 8$ Wehr C, Kivioja T, Schmitt C, Ferry B, Witte T, Eren E, Vlkova M, Hernandez M, Detkova D, Bos PR, Poerksen G, von Bernuth H, Baumann U, Goldacker S, Gutenberger S, Schlesier M, Bergeron-van der Cruyssen F, Le Garff M, Debre P, Jacobs R, Jones J, Bateman E, Litzman J, van Hagen PM, Plebani A, Schmidt RE, Thon V, Quinti I, Espanol T, Webster AD, Chapel H, Vihinen M, Oksenhendler E, Peter HH, Warnatz K: The EUROclass trial: defining subgroups in common variable immunodeficiency. Blood 2008;111:77-85.

9 Thickett KM, Kumararatne DS, Banerjee AK, Dudley R, Stableforth DE: Common variable immune deficiency: respiratory manifestations, pulmonary function and high-resolution CT scan findings. QJM 2002;95:655-662.
10 Rusconi F, Panisi C, Dellepiane RM, Cardinale F, Chini L, Martire B, Bonelli N, Felisati G, Pietrogrande MC: Pulmonary and sinus diseases in primary humoral immunodeficiencies with chronic productive cough. Arch Dis Child 2003;88:1101-1105.

11 Bondioni MP, Duse M, Plebani A, Soresina A, Notarangelo LD, Berlucchi M, Grazioli L: Pulmonary and sinusal changes in 45 patients with primary immunodeficiencies: computed tomography evaluation. J Comput Assist Tomogr 2007;31:620-628.

12 Chee L, Graham SM, Carothers DG, Ballas ZK: Immune dysfunction in refractory sinusitis in a tertiary care setting. Laryngoscope 2001;111:233-235.

13 Kruetzmann S, Rosado MM, Weber $\mathrm{H}$, Germing U, Tournilhac O, Peter HH, Berner R, Peters A, Boehm T, Plebani A, Quinti I, Carsetti R: Human immunoglobulin $M$ memory B cells controlling Streptococcus pneumoniae infections are generated in the spleen. J Exp Med 2003;197:939-945.

14 Carsetti R, Rosado MM, Donnanno S, Guazzi V, Soresina A, Meini A, Plebani A, Aiuti F, Quinti I: The loss of IgM memory B cells correlates with clinical disease in common variable immunodeficiency. J Allergy Clin Immunol 2005;115:412-417.

15 Detkova D, de Gracia J, Lopes-da-Silva S, Vendrell M, Alvarez A, Guarner L, Vidaller A, Rodrigo MJ, Caragol I, Espanol T, Hernandez M: Common variable immunodeficiency: association between memory B cells and lung diseases. Chest 2007;131:18831889.

16 Conley ME, Notarangelo LD, Etzioni A: Diagnostic criteria for primary immunodeficiencies. Representing PAGID (Pan-American Group for Immunodeficiency) and ESID (European Society for Immunodeficiencies). Clin Immunol 1999;93:190-197.

17 Standardization of Spirometry, 1994 Update. American Thoracic Society. Am J Respir Crit Care Med 1995;152:1107-1136.

18 Lund VJ, Mackay IS: Staging in rhinosinusitus. Rhinology 1993;31:183-184.
19 Lee JT, Kennedy DW, Palmer JN, Feldman M, Chiu AG: The incidence of concurrent osteitis in patients with chronic rhinosinusitis: a clinicopathological study. Am J Rhinol 2006;20:278-282.

20 Meltzer EO, Hamilos DL, Hadley JA, Lanza DC, Marple BF, Nicklas RA, Bachert C, Baraniuk J, Baroody FM, Benninger MS, Brook I, Chowdhury BA, Druce HM, Durham S, Ferguson B, Gwaltney JM Jr, Kaliner M, Kennedy DW, Lund V, Naclerio R, Pawankar R, Piccirillo JF, Rohane P, Simon R, Slavin RG, Togias A, Wald ER, Zinreich SJ; American Academy of Allergy, Asthma and Immunology; American Academy of Otolaryngic Allergy; American Academy of Otolaryngology-Head and Neck Surgery; American College of Allergy, Asthma and Immunology; American Rhinologic Society: Rhinosinusitis: establishing definitions for clinical research and patient care. Otolaryngol Head Neck Surg 2004;131(6 suppl):S1-S62.

-21 Meltzer EO, Hamilos DL, Hadley JA, Lanza DC, Marple BF, Nicklas RA, Adinoff AD, Bachert C, Borish L, Chinchilli VM, Danzig MR, Ferguson BJ, Fokkens WJ, Jenkins SG, Lund VJ, Mafee MF, Naclerio RM, Pawankar R, Ponikau JU, Schubert MS, Slavin RG, Stewart MG, Togias A, Wald ER, Winther B; The Rhinosinusitis Initiative: Rhinosinusitis: developing guidance for clinical trials. Otolaryngol Head Neck Surg 2006;135 (5 suppl):S31-S80.

22 Orange JS, Hossny EM, Weiler CR, Ballow M, Berger M, Bonilla FA, Buckley R, Chinen J, El-Gamal Y, Mazer BD, Nelson RP Jr, Patel DD, Secord E, Sorensen RU, Wasserman RL, Cunningham-Rundles C; Primary Immunodeficiency Committee of the American Academy of Allergy, Asthma and Immunology: Use of intravenous immunoglobulin in human disease: a review of evidence by members of the Primary Immunodeficiency Committee of the American Academy of Allergy, Asthma and Immunology. J Allergy Clin Immunol 2006;117(4 suppl):S525-S553. [Erratum in: J Allergy Clin Immunol 2006; 117:1483. Dosage error in article text.]

-23 Garau J, Calbo E: Community-acquired pneumonia. Lancet 2008;371:455-458.

-24 Goldacker S, Draeger R, Warnatz K, Huzly D, Salzer U, Thiel J, Eibel H, Schlesier M, Peter HH: Active vaccination in patients with common variable immunodeficiency (CVID). Clin Immunol 2007;124:294-303. 